Paper

\title{
Experimental and theoretical investigations of structural and thermoelectric properties of gallium doped $\mathrm{ZnO}$ thin films \\ ガリウム添加 Zn0 薄膜の構造・熱電特性の実験および理論的特性評価
}

\author{
Satoshi MORIKAWA, Tsukasa KOBAYASHI and Masayuki TAKASHIRI \\ Department of Materials Science, School of Engineering, Tokai University, 4-1-1 Kitakaname, \\ Hiratsuka, Kanagawa, 259-1292 Japan \\ TEL: +81-463-58-1211(EX.4203) FAX: +81-463-50-2096 e-mail: takashiri@tokai-u.jp \\ (Received 16 March, $2016 \quad$ Accepted 30 August, 2016)
}

We performed experimental and theoretical investigations of structural and thermoelectric properties of Ga-doped $\mathrm{ZnO}$ thin films. We prepared the thin films by a RF magnetron sputtering with various argon gas pressures, followed by thermal annealing at $500^{\circ} \mathrm{C}$ for $60 \mathrm{~min}$ in vacuum condition. We evaluated surface morphology and crystallographic properties as the structural properties of the $\mathrm{ZnO}$ thin films. To estimate the thermoelectric properties, we performed Hall measurement and the measurements of electrical conductivity, Seebeck coefficient and power factor. For theoretical analysis, we estimated an energy band structure of $\mathrm{ZnO}$ by first-principle calculation (ABINIT) based on density function theory with local density approximation, followed by the calculation of transport properties by BoltzTraP code. As a result, we found that the thin films at 2.0 Pa obtained the highest power factor of $0.73 \mu \mathrm{W} /\left(\mathrm{cm} \cdot \mathrm{K}^{2}\right)$. Even though the transport properties were exhibited certain differences between the experimental results and the theoretical results, we observed the approximate trend of the transport propeties of $\mathrm{ZnO}$.

Keywords: ZnO, Sputtering, Thermoelectric, First-principle calculation, ABINIT, BoltzTraP

\section{INTRODUCTION}

地球温暖化の原因とされる $\mathrm{CO}_{2}$ の削減のため, エネル ギーハーベスティングと呼ばれる既存技術では活用され ず廃棄されていたエネルギーを電力に変換する技術の開 発が行われている，そのなかに熱電材料による熱電発電 がある．熱電発電はゼーベック効果によって空気中など に放出される排熱を直接電力に変換することが可能であ る. 熱電発電の性能はパワーファクター $(P . F)$.$を 用いて評$ 価され, P.F. $=S^{2} \sigma$ で表せる. ここで $S$ はゼーベック係数, $\sigma$ は電気伝導率である.

熱電材料の多くは資源の希少性や遍在性による高価格 や供給の不安定性を抱えていたり，あるいはその構成元 素の人体への有毒性が懸念されている. これとは対照的 にバンドギャップ $3.4 \mathrm{eV}$ を持つ $\mathrm{n}$ 型半導体である $\mathrm{ZnO}$ は資源が潤沢かつ安全性が高い材料として知られている. $\mathrm{ZnO}$ はゴムの添加剤や医薬品, 化粧品として用いられて いるほか, 近年では透明電極への応用研究や熱電材料 の適用が検討されている。1

半導体の研究においては実際に試料を作製し, 特性を
評価する方法のほかに，近年ではコンピュータによるシ ミュレーションも行われてきている. その一つに半導体 の電子構造を理論的に求めることが出来る密度汎関数理 論に基づいた第一原理計算が確立されてきている。これ は固体材料の電気特性だけではなく輸送特性の計算にも 応用できる手法である.

薄膜の成膜方法にはめっき法, 2 真空蒸着法, 3 スパ ッタリング法 4 などが存在するが，我々はスパッタリン グ法の一種である RF マグネトロンスパッタリング法を 用いて $\mathrm{ZnO}$ 薄膜を成膜し, 成膜後試料にアニール処理を 行った。また，それらのデータを用いて第一原理バンド 計算および輸送特性解析を行い実験值と計算值の比較を 行った.

\section{EXPERIMNTAL METHOD}

$\mathrm{ZnO}$ 薄膜を $\mathrm{RF}$ マグネトロンスパッタリング装置 (Tokuda CFS-8EP)を用いて成膜した. ターゲットは直径 5.0 インチの高純度 $(99.99 \%)$ ターゲット $\mathrm{ZnO}(95$ at\%)-Ga(5.0 at\%)(高純度化学研究所製)を用いた．基板は 
ガラス基板(EAGLE XG)(縦: $30 \mathrm{~mm}$, 横: $20 \mathrm{~mm}$, 厚さ: 1.1 $\mathrm{mm}$ )を使用した。 成膜条件として, 雾囲気ガスは高純度 $\mathrm{Ar}$ ガス, 成膜圧力は $0.5,1.0,1.5,2.0 \mathrm{~Pa}$ の 4 パターン, 印加 RF パワーは $1000 \mathrm{~W}$ ，基板加熱は行わなかった。 ま た，膜厚を約 $1.0 \mu \mathrm{m}$ になるよう成膜時間を設定した.

成膜後のアニール処理は電気炉を用いた。ロータリー ポンプを作動させ炉内圧力を10 Paにしたままアニール 処理を行った.アニール温度は $500^{\circ} \mathrm{C}$ し, 昇温は $4 \mathrm{~K} / \mathrm{min}$ で行い, 所定のアニール温度で60分間保持した。アニー ル処理後, 炉内の温度が $100^{\circ} \mathrm{C}$ 以下になったことを確認 した後で試料を取り出した.

構造的特性として走査型電子顕微鏡 $(\mathrm{SEM})$ による表面 観察とX 線回折による結晶学特性を評価を行った. 結晶 粒径はX 線回折を用いて得られた回折強度の半值幅から シェラーの式を用いて平均結晶子サイズを算出した。ま た，格子定数は以下の式で算出した.

$$
1 / d^{2}=4 / 3 \cdot h^{2}+h k+k^{2} / a^{2}+l^{2} / c^{2}
$$

式(1)の $d$ は面間隔, $a$ は $a-b$ 軸方向の格子定数, $c$ は $c$ 軸方向の格子定数, $h, k, l$ はミラー指数を表している.

電気的特性として電気伝導率 $\sigma$, ゼーベック係数 $S$ とパ ワーファクターP.F. $\left(P . F .=S^{2} \sigma\right)$ を室温下で評価した. 電気 伝導率は4探針抵抗測定装置(NAPSON, RT-70V)を用いて 測定した. ゼーベック係数の測定では, 成膜した試料を ヒートシンクとヒータ間に置き, その表面にK熱電対を 固定し, 膜面方向に温度差を0〜 $4 \mathrm{~K}$ 与えたときに発生す る熱起電力から算出した. 得られた熱起電力にはK熱電 対の材料であるアルメルとクロメルの熱起電力を含んで いるため, その分を差し引いて熱電薄膜のみのゼーベッ ク係数を算出した. パワーファクターP.F.は得られた電 気伝導率 $\sigma$ とゼーベック係数 $S$ から算出した.

\section{CALCULATION METHOD}

Fig. 1にZnOの結晶構造を示す. $\mathrm{ZnO}$ は空間群P63mcに 属している六方晶構造の結晶である. 格子定数は $\mathrm{a}=\mathrm{b}=3.253 \AA, c=5.210 \AA$, 軸角はそれぞれ $\alpha=\beta=90^{\circ}, \gamma=120^{\circ}$ となる. 本研究における格子定数の值はX回折装置によ る測定結果の值を用いた.

第一原理バンド計算にはオープンソースソフトウェア であるABINITを用いた. ${ }^{5} \mathrm{ABINIT} は$ 平面波法と擬ポテン シャル法を組み合わせた計算プログラムである.

また輸送特性解析にはBoltzTraPを用いた。 ${ }^{6}$ BoltzTraP はボルツマン方程式に従って輸送係数を求めることがで き, 電気伝導率やゼーベック係数を理論的に求めること が出来る計算プログラムである.

本研究の計算条件はk点メッシュを $12 \times 12 \times 12$, カット

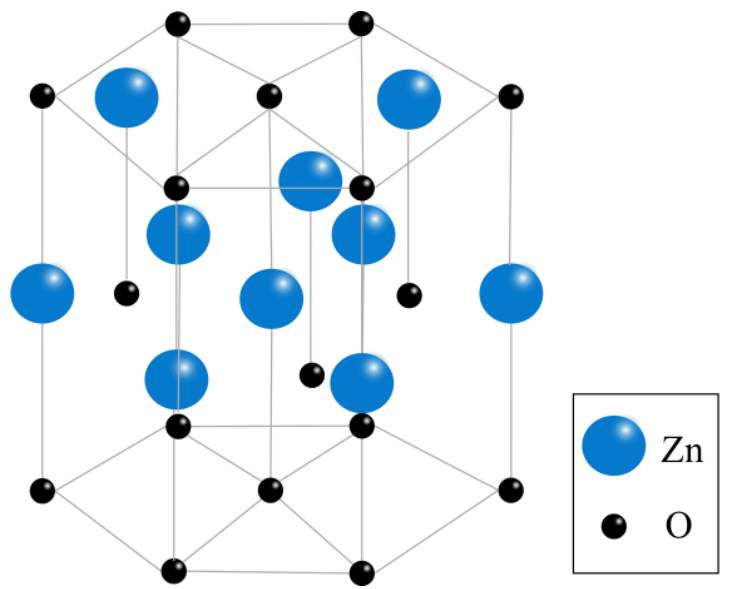

Fig. 1. Schematic crystal structure of $\mathrm{ZnO}$.

オフエネルギーを40 Hartreesに設定した。近似法は局所 密度近似(Local Density Approximation, LDA)を用いた。ま た，系を単純化するために， Ga原子を計算に含めていな い. BoltzTraPに用いたホール係数の值はホール効果測定 法により求め, 緩和時間は $3.0 \times 10^{-15} \mathrm{~s}$ に固定して解析を行 った.

\section{RESULTS AND DISCUSSION}

Fig. 2 に ZnO 薄膜の表面 SEM 画像を示寸. 成膜圧力の 変化よる表面組織の変化は観察されなかった.

Fig. 3 に $\mathrm{ZnO}$ 薄膜の $\mathrm{X}$ 線回折結果を示寸. 全ての試料 で(002)のピークを示した. 成膜圧力が $1.5 \mathrm{~Pa}$ の時最も強 いピークが得られた。

Fig. 4 に結晶子サイズ, 配向性, 格子定数と成膜圧力
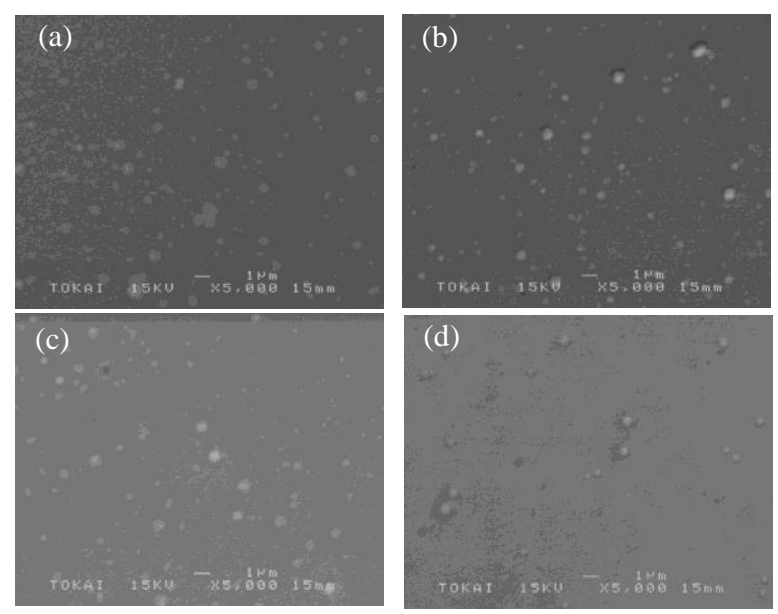

Fig. 2. Surface morphologies of $\mathrm{ZnO}$ films on glass substrates imaged using SEM. (a)-(d) are images of $\mathrm{ZnO}$ films that deposited at various argon sputtering pressure as 0.5 $\mathrm{Pa}, 1.0 \mathrm{~Pa}, 1.5 \mathrm{~Pa}$ and 2.0 $\mathrm{Pa}$ respectively. Therefere, samples were annealed of $500^{\circ} \mathrm{C}$. 


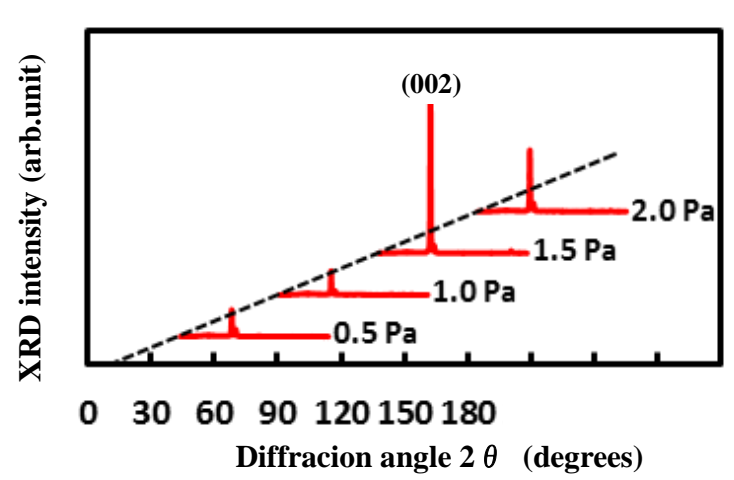

Fig. 3. X-ray diffraction patterns of $\mathrm{ZnO}$ films.

の関係を示す、結晶粒径は成膜圧力に大きな影響を受け ない傾向が見られた。最大結晶子サイズは $1.5 \mathrm{~Pa}$ の時 $59.5 \mathrm{~nm}$ であった。配向性はわずかであるが成膜圧力の 増加にともない増加することが見られた. 最大の配向性 は $1.5 \mathrm{~Pa}$ の時 0.96 であった. 格子定数は成膜圧力による 影響が全く見られず， $a-b$ 軸方向の格子定数は $3.3 \AA, c$ 軸方向の格子定数は $5.2 \AA$ であった.

Fig. 5 にホール効果測定から得られたホール係数，キ ヤリア濃度，キャリア移動度と成膜圧力の関係を示す。 ホール係数およびキャリア移動度は成膜圧力の増加に ともない増加寸る傾向が見られたが， $2.0 \mathrm{~Pa}$ の時急激に

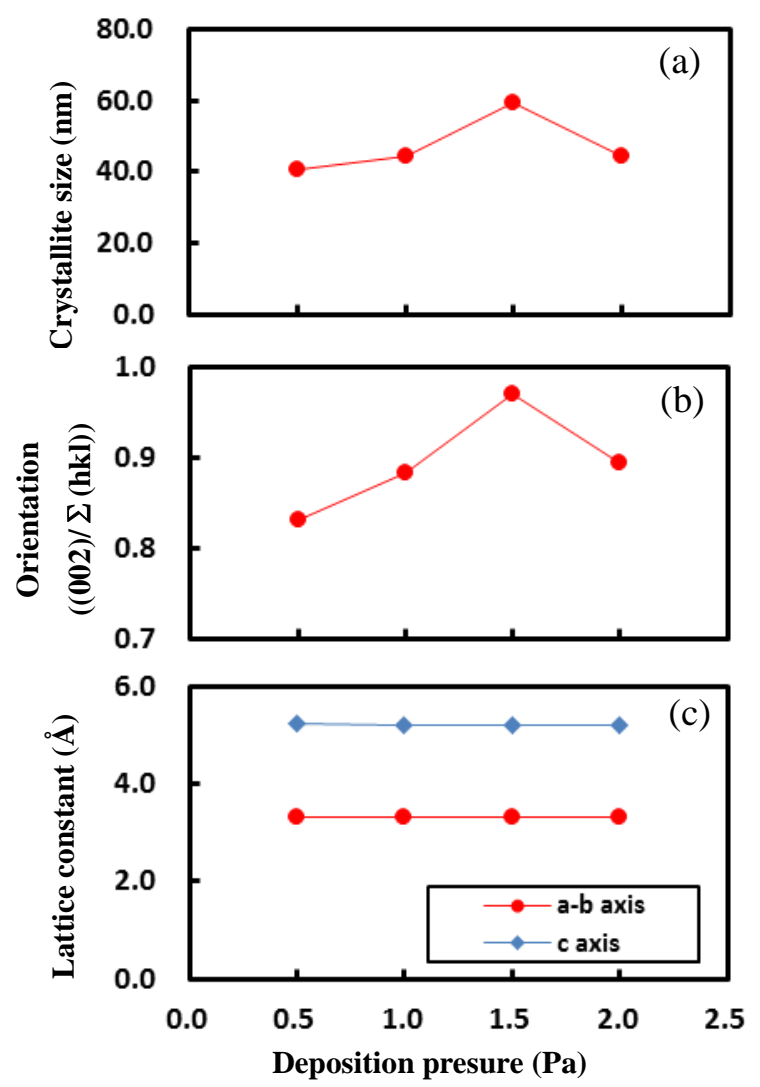

Fig. 4. Crystallite size, crystal orientation and lattice constants as a function of deposition pressure.

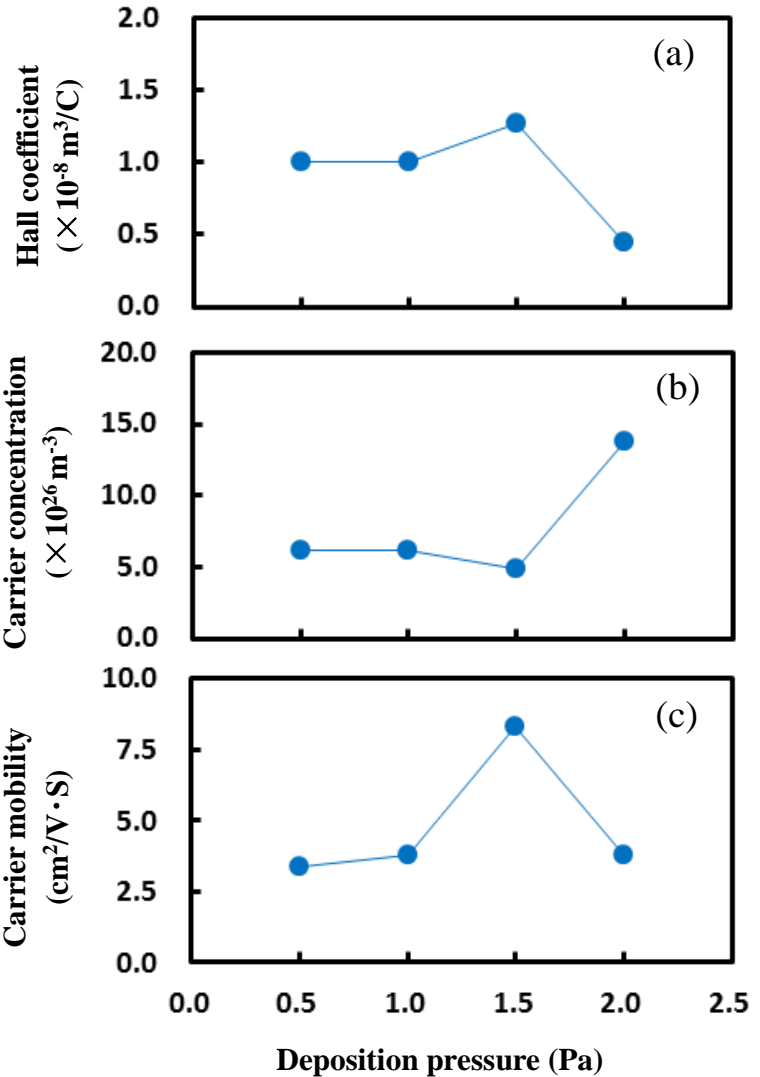

Fig. 5. Hall coefficient, carrier concentration and mobility as a function of deposition pressure.

減少した. 反対にキャリア濃度は成膜圧力が増加にとも ない減少していく傾向だが, $2.0 \mathrm{~Pa}$ の時急激に増加した. これらの理由として $1.5 \mathrm{~Pa}$ の時最も配向性が高くなって いることによりキャリア移動度が高くなったと考えられ る.

Fig. 6 に第一原理計算から得られた $\mathrm{ZnO}$ のエネルギー バンド図を示す．バンドギャップ底部に位置する価電子 帯のほとんどは酸素の $p$ 軌道からなり, バンドギャップ 上部に位置する伝導体は主に亜鉛の $d$ 軌道からなる。 バ ンドギャップは「点で最少の $1.039 \mathrm{eV}$ となり，これは一 般的に知られている $\mathrm{ZnO}$ バンドギャップの $3.4 \mathrm{eV}$ と比較 するとかなり小さな值になった。 その理由としては今回 用いた近似法の LDA はバンドギャップを過小評価する 傾向があるためだと考えられる。7

Fig. 7 に電気伝導率，ゼーベック係数，P.F.の実験值お よび計算值と成膜圧力の関係を示す．実験值において電 気伝導率は成膜圧力の増加にともない増加する傾向が見 られた。最大電気伝導率は $2.0 \mathrm{~Pa}$ の時, $830 \mathrm{~S} / \mathrm{cm}$ であっ た。ゼーベック係数は成膜圧力に大きな影響をうけない ことが見られ, 最大ゼーベック係数は-33.4 $\mu \mathrm{V} / \mathrm{K}$ であっ 


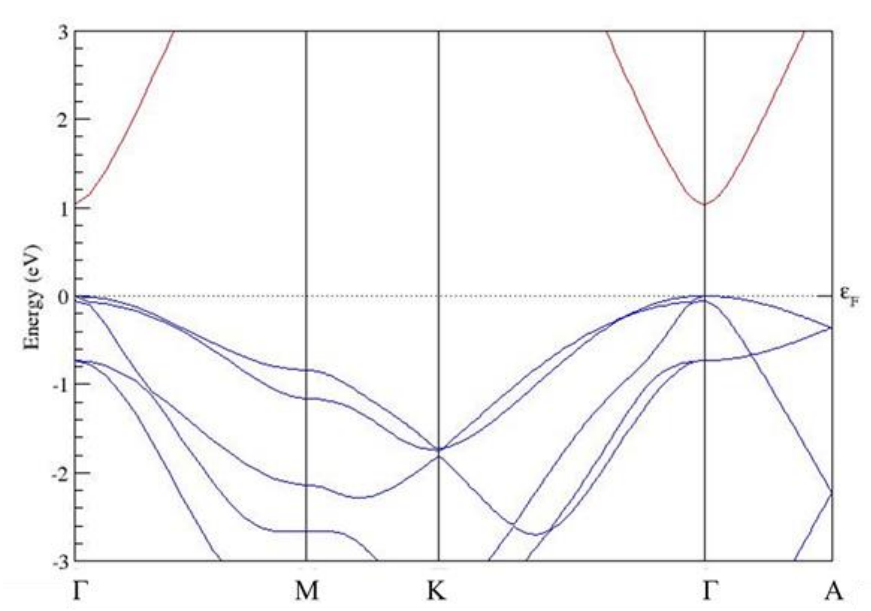

Fig. 6. Energy band structure of $\mathrm{ZnO}$.
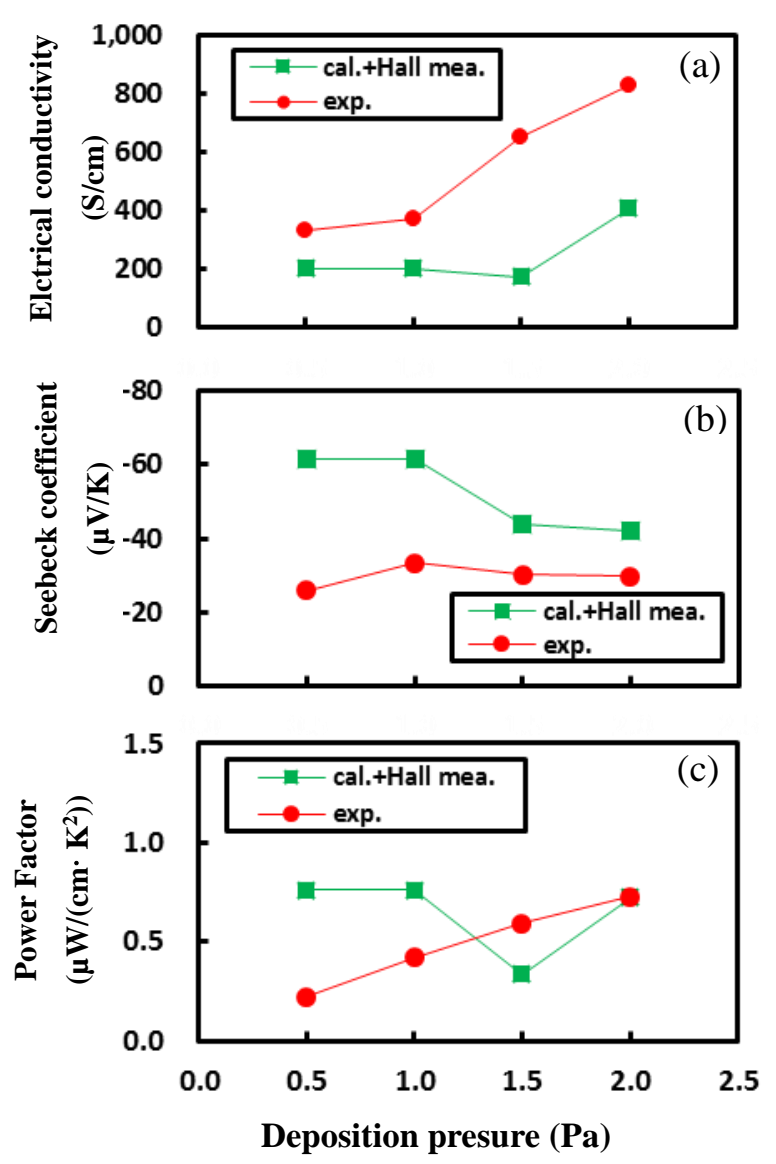

Fig.7. Elctrical conductivity, Seebeck coefficient and Power Factor as a function of deposition pressure.

た.P.F.は成膜圧力ともに増加することが見られ最大 P.F. は $0.72 \mu \mathrm{W} /\left(\mathrm{cm} \cdot \mathrm{K}^{2}\right)$ であった。

次に輸送特性の解析計算の結果を示寸。電気伝導率は 成膜圧力の増加にともない増加する傾向が見られ, 実験 結果と解析結果で電気伝導率の大きさは異なるものの, 同様な傾向が見られた，ゼーベック係数については，成
膜圧力の増加にともない減少する傾向が見られ，実験結 果と傾向においても差異が見られた。P.F.は電気伝導率 とゼーベック係数を掛け合わせたものなのでゼーベッ ク係数が高く出た $0.5 \mathrm{~Pa}, 1.0 \mathrm{~Pa}$ のものが高くなった. 全体として, 熱電特性の実験結果と解析結果を比較した 場合，改良の余地はあるものの，簡単な系を用いた計算 においてもある程度の傾向を把握することが可能であ ることが分かった。本研究では，第一原理計算において 系の単純化のために $\mathrm{Ga}$ ドープの効果を取り入れていな い. $\mathrm{Ga}$ は $\mathrm{ZnO}$ 格子中の $\mathrm{Zn}$ と置換されることが知られて おり, $\mathrm{Zn}$ が $\mathrm{Ga}$ に置き換わることでバンド構造に差異が 生じ，それが輸送特性に影響を与えたのではないかと推 測できる. 8

\section{CONCLUSION}

本研究では熱電材料の $\mathrm{ZnO}$ 薄膜を $\mathrm{RF}$ マグネトロンス パッタリング装置を用いて成膜した．成膜条件としては 成膜圧力を変化させながら成膜を行い，その後アニール 処理を施した。また，それらの試料を理論的に評価する ために第一原理バンド計算および輸送特性の解析を行っ た。構造的特性においては SEM およびX 線回折装置を 用いて評価を行った。表面 SEM 画像により成膜圧力に よる表面組織の変化は見られなかった。成膜圧力の変化 による格子定数の変化は見られなかったが, 配向性およ び結晶粒径においては成膜圧力が $1.5 \mathrm{~Pa}$ の時に最も高い 值が得られた。熱電特性では, 成膜圧力が増加するにつ れて電気伝導率は向上し, ゼーベック係数は顕著な変化 は見られなかった。 その結果, 成膜圧力 $2.0 \mathrm{~Pa}$ において 最大の P.F. $\left[0.72 \mu \mathrm{W} /\left(\mathrm{cm} \cdot \mathrm{K}^{2}\right)\right]$ が得られた。熱電特性の実 験結果と解析結果を比較した場合，改良の余地はあるも のの, 簡単な系を用いた計算においてもある程度の傾向 を把握することが可能であることが分かった。

\section{ACKNOWLEDGEMENTS}

本研究のホール効果測定に協力していただいた東海大 学の沖村邦雄教授、薄膜の評価・分析に協力していただ いた東海大学の初田直樹大学院生、第一原理計算及び輸 送特性解析に協力していただいた東海大学の稲本拓也大 学院生に感謝する.

\section{REFERENCES}

${ }^{1}$ P. Mele et al., Appl. Phys. Lett., 102, 253903 (2013).

${ }^{2}$ K. Matsuoka et al., J. Alloys Compd, 649, 721 (2015). 
${ }^{3}$ M. Takashiri et al., J. Electron. Mater., 43, 1881 (2014).

${ }^{4}$ K. Kusagaya et al., J. Electron. Mater., 44, 1632 (2015).

${ }^{5}$ X. Gonze, et al., Comput. Mater. Sci., 25, 478 (2002).
${ }^{6}$ G. K. H. Madsen et al., Comput. Phys. Commun., 175, 67 (2006).

${ }^{7}$ A. Rubio et al., Phys. Rev. B: Condens. Matter., 49, 5081 (1994).

${ }^{8}$ S. Jantrasee et al., J. Electron. Mater., 43, 1689 (2014). 